\title{
Sustavni pregled - \\ podloga medicini utemeljenoj na znanstvenim spoznajama
}

${ }_{1,3}^{3}$ Miljenko Franić

${ }^{1,3}$ Stjepan Dokuzović

2 Jelka Petrak

1 Zavod za traumatologiju i ortopediju, Klinika za kirurgiju, Klinička bolnica Dubrava, Zagreb

2 Središnja medicinska knjižnica, Medicinski fakultet sveučilišta u Zagrebu

3 Zdravstveno veleučilište Zagreb

\section{Sažetak}

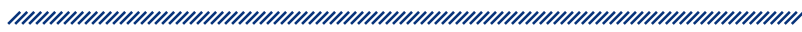

U ovom članku opisuju se temeljna načela izrade sustavnog pregleda i metaanalize. Izdvojene su važne značajke koje se odnose na postavljanje specifičnoga kliničkog pitanja, prikupljanje objavljenih studija, kritičku procjenu podataka i objedinjavanje znanstvenih spoznaja. Glavni je cilj ovog rada potaknuti što više medicinskih djelatnika da se u svakodnevnom donošenju kliničkih odluka služe najboljim dostupnim spoznajama iz literature te da se i sami okušaju u izradi kvalitetnoga sustavnog pregleda.
Ključne riječi: sustavni pregled, metaanaliza, medicina utemeljena na znanstvenim spoznajama

Datum primitka: 14.02.2016

Datum prihvaćanja: 01.12.2016.

Adresa za dopisivanje:

dr. sc. Miljenko Franić, prof. v.š.

Zavod za traumatologiju i ortopediju, KB Dubrava

Avenija Gojka Šuška 6, 10000 Zagreb

Tel. 01/290-3631

E-pošta: mfranic@kbd.hr

\section{Uvod}

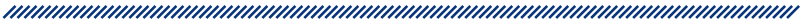

Liječnici su se uvijek koristili preglednim člancima kao sažetim prikazom objavljenih radova o nekoj određenoj temi u nekom određenom razdoblju. Te su tzv. narativne pregledne članke u pravilu pisali (i danas pišu) eksperti iz pojedinih područja koji su prikazivali rezultate samo onih istraživanja koji su po njihovoj osobnoj prosudbi sadržavali vrijedan znanstveni doprinos, pri čemu se vrlo često ne navodi detaljan prikaz načina odabira, ocjene i analize uključenih znanstvenih radova. Budući da se vrijednost preglednog rada temelji prije svega na njegovoj metodološkoj pouzdanosti ${ }^{1}$, takvi pregledni članci nose velik rizik pristranosti i nesustavnosti ${ }^{2}$. Nasuprot tome stoji sustavni pregled, koji Cook i sur. de- 
finiraju kao „primjenu znanstvene strategije kojom se sustavnim prikupljanjem, kritičkom ocjenom i sintezom relevantnih istraživanja na neku određenu temu ograničava pristranost (engl. bias)“3 te time povećava pouzdanost i točnost izvedenih zaključaka.

Kvaliteta narativnoga preglednog rada najčešće se prosuđuje po ugledu autora i časopisa u kojemu je takav pregled objavljen, dok se kvaliteta sustavnoga pregleda procjenjuje na temelju razine kojom su se slijedila unaprijed postavljena pravila i postupci u pretraživanju, analizi i sintezi znanstvenih dokaza4 ${ }^{4}$ Stupnjevi značajnosti (engl. levels of evidence), odnosno hijerarhija snage dostupnih dokaza vezuju se uz vrstu kliničke studije, odnosno istraživanja. Randomizirana kontrolirana klinička istraživanja smatraju se izvorom najveće dokazne snage u hijerarhiji dokaza koji se upotrebljavaju u prosudbi djelotvornosti neke intervencije ili terapijske metode ${ }^{5}$. Ta hijerarhija dokaza najprije je opisana u izvješću Canadian Task Force on the Periodic Health Examination iz 1979. godine ${ }^{6}$. Na toj ljestvici prvo mjesto zauzimaju dokazi iz barem jedne randomizirane kliničke studije $\mathrm{s}$ pravilno provedenom randomizacijom. U kategoriji II.1. nalaze se dobro planirana kohortna istraživanje ili istraživanja parova i kontrola, a u kategoriji II.2. usporedba vremenskih serija ili važni nalazi iz nekontroliranih studija. Najmanju snagu, odnosno razinu značajnosti ima mišljenje eksperata (razina III.). Razine značajnosti kasnije je podrobno opisao Sackett ${ }^{7}$ u svojem članku o antitrombotičkim lijekovima. Najveću razinu značajnosti (I.) imaju dokazi iz velikih randomiziranih kliničkih studija, na razini II. nalaze se male randomizirane kliničke studije, na razini III. kohortne studije i studije parova, na razini IV. povijesna kohortna istraživanja i istraživanja parova i kontrola, dok su na razini V. serije slučajeva i istraživanja bez kontrole.

Sustavni pregledi objavljene literature odgovaraju na jedno ili više kliničkih pitanja pronalaženjem, kritičkom prosudbom i integriranjem rezultata svih relevantnih pojedinačnih (primarnih) istraživanja. U području kliničke medicine danas se najčešće primjenjuju u ocjeni terapijskoga postupka, primjerenosti i točnosti dijagnostičkih postupaka i prognozi ishoda.

Kritička prosudba i sinteza istraživačkih podataka na sustavan način prvi se put pojavila u člancima Glassa i suradnika osamdesetih godina prošloga stoljeća ${ }^{8}$. Danas se zlatnim standardom smatraju sustavni pregledi izrađeni u skladu s metodologijom Kolaboracije Cochrane ${ }^{9,10}$.

U izradi sustavnih pregleda rabi se metodologija slična onoj koja se primjenjuje u ostalim oblicima istraživačkoga rada: a) postavljanje provjerljive hipoteze, odnosno jasnoga istraživačkog pitanja

b) utvrđivanje strategije pretraživanja baza podataka i članaka

c) primjena unaprijed definiranih kriterija uključivanja i isključivanja pronađenih članaka

d) kritička ocjena uključenih članaka/istraživanja

e) izlučivanje i sažimanje rezultata

f) oblikovanje nalaza ${ }^{11}$.

\section{Metodologija izrade sustavnog pregleda}

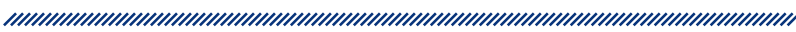

Sustavni pregled sekundarno je istraživanje kojim se naknadno obrađuju podatci dobiveni u izravnim (primarnim) istraživanjima ${ }^{12,13}$. Mora imati jasno definirane ciljeve, dobro formulirana pitanja (o bolesniku, intervenciji, ishodu) na koje se traži odgovor, na sveobuhvatan način identificirati, odabirati, i kritički ocjenjivati relevantna primarna istraživanja te konačno analizirati i sažimati podatke iz odabranih radova ${ }^{14}$. To zahtijeva timski pristup ${ }^{15}$, vještinu probira objavljene literature, stručno i kritičko razmatranje tematike, izbjegavanje otklona ili pristranosti (engl. bias)* te poznavanje metoda statističke analize.

Ciljevi sustavnoga pregleda uvijek su isti: povećati znanje o stupnju značajnosti provedenih kliničkih studija i pronađenih znanstvenih dokaza, ali mogu biti ispunjeni na različite načine: (a) objašnjenje relativne snage i slabosti uključene literature, (b) sažimanje velikog broja objavljenih radova o nekom predmetu, (c) razrješavanje prijepora objavljenih u literaturi o nekom predmetu, (d) procjena potrebe za provođenjem daljnjih kliničkih pokusa, (e) dokazivanje suvišnosti provođenja nekog kliničkog pokusa, (f) povećanje statističke snage rezultata manjih pokusa, (g) identifikacija ili povećanje preciznosti terapijskog učinka i (h) povećanje poopćivosti terapijskoga ishoda ${ }^{16}$.

* Prema Rječniku statističkoga nazivlja biomedicinskih istraživanja (vidi http://mi.medri.hr/assets/rjecnik_pojmova.pdf) engleski pojam bias definira se kao „odstupanje rezultata ili zaključaka od istine, što rezultira pojavom sustavne pogreške, ili postupak koji vodi takvom odstupanju“. 
Izrada sustavnog pregleda mora imati jasnu i dosljednu strukturu baziranu na formatu IMRaD (engl. Introduction, Methods, Results and Discussion). Svaki dio strukture podjednako je važan, jer kvaliteta sustavnoga pregleda ovisi o dosljednosti i preciznosti provođenja svakog dijela, a ne samo o kvaliteti statističke analize. Plan istraživanja mora se razraditi unaprijed, tzv. bias se mora svesti na najmanju moguću mjeru u svakoj fazi izrade sustavnoga pregleda, kriteriji uključenja/isključenja moraju biti unaprijed definirani i u potpunosti objašnjeni, strategija pretraživanja literature mora biti što opsežnija, suglasnost sudionika istraživanja mora se postići oko svih ključnih odluka, a metaanalizu treba uključiti kad je to moguće. U pripremi i tijekom provođenja sustavnoga pregleda mogu se upotrebljavati referentni priručnici i smjernice ${ }^{17,18}$.

\section{Postavljanje kliničkoga istraživačkog pitanja: što se želi dokazati?}

Dobro postavljeno kliničko pitanje i dobro razrađen protokol istraživanja preduvjet su uspješnosti izrade sustavnoga pregleda. Pri tome se preporučuje preliminarni pregled literature kako bi se glavno pitanje moglo što bolje oblikovati, ovisno o trenutačnim saznanjima o temi i potrebama kliničke prakse. Pitanje ne smije biti preusko definirano jer će rezultirati pronalaženjem malog broja relevantnih primarnih studija za uključenje u sustavni pregled. Ako je pitanje postavljeno preširoko, tada će biti teško donijeti klinički korisne zaključke. Pitanja se obično postavljaju po tzv. obrascu PICO (od engl. Patient/Population, Intervention, Comparison, Outcome) koje obuhvaća populaciju ili skupine koje će se istraživati, intervenciju na populaciji, usporednu intervenciju ili kontrolu te ishod, odnosno rezultat intervencije.

\section{Plan istraživanja: kako provesti istraživanje?}

Ovaj postupak odnosi se na definiranje kriterija uključenja/isključenja radova u sustavni pregled. Strategija pronalaženja svih relevantnih istraživanja oblikuje se u pisanom obliku i sadrži način probiranja i izdvajanja (pri čemu se svako isključenje nekog istraživanja mora opravdati), vrste primarnih istraživanja koja će biti uključena u pregled (obično su to istraživanja s velikom snagom dokaza, tj. randomizirani kontrolirani pokusi), osobitosti populacije obuhvaćene istraživanjem (primjerice dob) te način izbjegavanja svakog oblika tzv. biasa (potrebno je, na primjer, kad je god to moguće razmotriti i uključiti rezultate neobjavljenih istraživanja, čime se otklanja bias prema javno dostupnim istraživanjima; bias prema publikacijama na engleskom jeziku itd.). Protokoli su potrebni zbog kritičkog procjenjivanja sustavnih pregleda te se obično objave prije početka samog istraživanja. Na taj način čitatelji mogu dati prijedloge za poboljšanje metodologije te omogućiti daljnje smanjenje biasa. Time se također može izbjeći nepotrebno dupliciranje istraživanja ako drugi istraživači istodobno planiraju napraviti isto ili slično istraživanje.

\section{Pretraga literature: koje radove treba raz- motriti za uključenje u sustavni pregled?}

Nakon formuliranja kliničkoga pitanja i razrade protokola slijedi jedna od najvažnijih faza u izradi sustavnoga pregleda - opsežno pretraživanje vjerodostojnih bibliografskih izvora radi pronalaženja što više relevantnih radova o postavljenom kliničkom pitanju. Pretraživanje se ne smije ograničiti samo na jednu bazu podataka, pa čak ni samo na objavljene radove, a sve u svrhu postizanja sveobuhvatnosti, odnosno izbjegavanja biasa u izboru radova za analizu. Greške u pretraživanju mogu utjecati na nepotpunost uključenoga dokaznog materijala, a time i na kvalitetu sustavnoga pregleda ${ }^{19}$.

Strategiju pretraživanja treba započeti raščlanjivanjem kliničkoga pitanja u pojmove s pomoću kojih će se pretraživati i kasnije kombinirati rezultate. Pri tome treba uzeti u obzir sve poznate varijante i istoznačnice ključnih pojmova te sve primjerene alate koje pružaju baze podataka: ključne riječi, riječi iz naslova i sažetka, pojmove iz tezaurusa (npr. MeSH), različite filtre (primjerice dobne skupine, vrstu publikacije, jezik) i sl. ${ }^{20}$ Poznavanje područja i područnog nazivlja može znatno doprinijeti preciznosti rezultata pretraživanja. Pretraživanje treba provesti u najmanje dvije, a poželjno je i u više baza podataka. Spominjemo samo one biomedicinske baze podataka koje se najčešće upotrebljavaju. Najopsežnija baza podataka MEDLINE, odnosno besplatno dostupna inačica te baze PubMed, omogućava uvid u više od 28 milijuna bibliografskih zapisa o člancima iz medicinskih časopisa ${ }^{21}$. U pretrazi PubMeda treba iskoristiti sve prednosti te baze, poput kontroliranog rječnika MeSH, filtra za vrstu publikacije (npr. metaanaliza, randomizirani klinički pokus - RCT, klinički pokus, sustavni pregled) te filtra za postavljanje kliničkih pitanja (PubMed Clinical Queries). Multidisciplinarna bibliografska baza Scopus sadržava veliki broj medicinskih informacija, a s obzirom na to da uključuje više medicinskih izvora nego PubMed, treba obaviti pretragu upotrebljavajući prije svega precizne pojmove koji bi se mogli naći u naslovu, sažetku ili u ključnim autorskim riječima pojedinih 
članaka ${ }^{22}$. Za područje sestrinstva i ostalih primijenjenih zdravstvenih djelatnosti važna je baza podataka CINAHL (Cumulative Index of Nursing and Allied Health Literature) koja donosi informacije objavljene u različitim izvorima (časopisni članci, disertacije, knjige i konferencijski zbornici) ${ }^{23}$.

Posebno treba izdvojiti Cochrane Library i baze podataka koje je sačinjavaju kako za pretraživanje dostupnih sustavnih pregleda (Cochrane Database of Systematic Reviews) tako i za identifikaciju kontroliranih kliničkih pokusa (Cochrane Central Register of Controlled Trials) ${ }^{24}$.

Strategiju pretraživanja i pojmove koji su se rabili u pretraživanju literature obvezno treba uključiti u rukopis sustavnoga pregleda.

Radi obuhvata svih provedenih kliničkih istraživanja ponekad može biti potrebno pregledati i ograničeno dostupne publikacije, poput doktorskih radnji, lokalnih časopisa i sl.

Za pohranu i organizaciju referencija za daljnju obradu od velike koristi mogu biti komercijalni (EndNote, ProCite, ili Reference Manager) ili besplatno dostupni programi za upravljanje referencijama (Zotero, Mendeley), pogotovo kad više osoba radi na ovom postupku.

\section{Izlučivanje podataka: kako prepoznati važnost primarnih istraživanja za uključenje u sustavni pregled?}

U ovoj fazi svi se pronađeni radovi analiziraju prema unaprijed postavljenim kriterijima uključenja/isključenja. Taj korak najčešće zahtijeva suradnju barem dvaju istraživača kako bi probiranje literature bilo što potpunije i temeljitije. Ponekad se to može učiniti na temelju naslova i/ili sažetka rada, ali je najčešće potrebno analizirati rad u cijelosti. Iz svih radova koje se odluči uključiti u sustavni pregled potrebno je izlučiti podatke za daljnju analizu. Ti se podatci mogu upisivati u pripremljene obrasce (elektroničke ili papirne) radi lakše preglednosti. U takve obrasce najčešće se unose: potpuna referencija, cilj istraživanja, vrsta istraživanja, demografska skupina, intervencija, opis kontrolne skupine ili alternativne intervencije, ishod intervencije te dodatni komentari. Neki podatci mogu se kodirati. Nakon izlučivanja podataka donosi se konačna odluka o uključivanju odnosno isključivanju radova za daljnju analizu. Korisno je navesti razloge za isključivanje, jer kasnije to može biti potrebno obrazložiti recenzentima sustavnoga pregleda.

\section{Procjena kvalitete: zadovoljava li istraživanje sve kriterije za uključenje u sustavni pregled?}

Nakon što se preliminarnim pregledom izdvoje svi relevantni radovi, potrebno je utvrditi jesu li odabrana istraživanja usporediva $\mathrm{i}$ je li metodologija provedbe na dovoljno visokoj razini kako bi zavrijedila konačno uključenje u sustavni pregled. To zahtijeva kritičko procjenjivanje izvedbe istraživanja kako bi se na najmanju moguću mjeru smanjili ili potpuno isključili razni oblici tzv. biasa. Glavni su oblici tzv. biasa: selekcijski bias (jesu li pacijenti uistinu nasumično podijeljeni u skupine), bias u provođenju istraživanja (je li intervencija prikrivena, odnosno je li, primjerice, terapija nepoznata pacijentu i istraživaču), bias opažanja (jesu li ishodi prikriveni odnosno nepoznati pacijentu i istraživaču), atricijski bias (jesu li autori obrazložili svaki „gubitak" pacijenta u praćenju), publikacijski bias (odstupanja zbog pretežitog objavljivanja određenog tipa istraživanja) te bias u izvješćivanju o ishodu. Postoje razni alati za bodovanje kriterija kvalitete, kao što je primjerice Cochrane Risk of Bias Tool za procjenjivanje pouzdanosti randomiziranih kontroliranih studija ${ }^{25}$.

Osobito je važno da odabir i vrjednovanje provodi tim stručnjaka sačinjen od kliničara koji poznaju područje interesa te statističara. Nakon što su radovi odabrani na osnovi precizno postavljenih kriterija, slijedi obrada i izdvajanje podataka važnih za analizu.

\section{Analiza i interpretacija podataka: što smo doznali sabirući podatke i rezulta- te svih istraživanja?}

Rezultate pojedinih studija treba združiti kako bi se donio zaključak o kliničkoj djelotvornosti ili svrhovitosti neke intervencije. Taj se postupak naziva sintezom dokaza. Pri tome treba razmotriti i odabrati najbolji postupak kako za kombiniranje i usporedbu podataka iz različitih istraživanja tako i za testiranje razlike među njima. Ako kvantitativni podatci nisu homogeni, oblikuju se narativni sažetci. Kad su rezultati pojedinačnih studija homogeni i pouzdani, metaanaliza predstavlja snažan alat kojim se razrješavaju dvojbe i rezultati čine preciznijima. 


\section{Znanstvene sastavnice metaanalize}

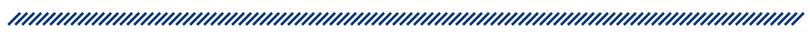

Metaanaliza je postupak kojim se, primjenom statističkih metoda, objedinjavaju i kombiniraju rezultati više individualnih studija koje proučavaju istu pojavu. Time se pojačava snaga analize i dokaza. Konzistentnost podataka iz različitih studija koji bi se objedinili metaanalizom ključni su za pouzdanost rezultata. Preciznost i pouzdanost rezultata dobivenih takvom statističkom sintezom u pravilu je veća od preciznosti i pouzdanosti bilo koje pojedinačne studije, uz uvjet da su zadovoljene određene pretpostavke u postupku izbora studija koje će se uzeti u obzir pri metaanalizij ${ }^{26}$.

Primjena statističkih postupaka koji stoje u pozadini metaanalitičkog izračuna moguća je na bilo kojem skupu podataka, ali u većini je slučajeva smislena samo ako su studije sustavno prikupljene. Zbog toga se metaanalizu može smatrati statističkim prikazom podataka prikupljenih sustavnim pregledom, odnosno normiranom kvantifikacijom nalaza prikupljenih sustavnim pregledom. Kod pripreme metaanalize potrebno je navesti svaki članak koji se uključuje u metaanalizu, broj ispitanika u svakoj skupini, vrstu opisane intervencije, nacrt studije te metodu određivanja stupnja kvalitete studije.

Upotreba metaanalitičke statistike vrlo je slična onoj koja se primjenjuje u primarnim istraživanjima. Formule upotrijebljene u metaanalizi nadogradnja su formula primijenjenih u primarnim istraživanjima i daju odgovor na slična pitanja koja se u njima postavljaju. Objedinjena procjena dobiva se uprosječivanjem rezultata pojedinačnih studija na poseban način, što pouzdanijim studijama daje veći utjecaj na ukupan rezultat. Metaanalitički postupak u svojoj se srži svodi na određivanje težinskih faktora (pondera) za svaku pojedinu studiju koje se zatim primjenjuje pri izračunu ukupnog rezultata. Matematičke formule koje se primjenjuju pri izračunu vrijednosti za metaanalizu drugdje su detaljno opisane, ${ }^{27}$ a dostupni su i računalni alati za brzu i točnu izradu metaanaliza (npr. Comprehensive Meta-Analysis, Biostat Inc., Englewood, New Jersey).

Bez obzira na znanstveno područje ili vrstu pojave koju se proučava, predmet metaanalize u pravilu je veličina $i$ postojanost određenog učinka.

Za kliničku je znanost i praksu metaanaliza važna jer:

1. omogućava pregled $\mathrm{i}$ analizu rezultata određene skupine članaka na konzistentan, objektivan i standardiziran način
2. omogućava kombiniranje podataka iz dovoljno homogenih članaka radi procjene vrijednosti rezultata te tako nadilazi rizik pojave lažno negativnih rezultata zbog studija s malim uzorkom

3. otkrivajući izvore heterogenosti među studijama, metaanaliza može koristiti za razvijanje teorija o razlozima pojava varijabilnosti među studijama te tako davati smjernice za planiranje novih studija ${ }^{28}$.

Poželjno je da ekstrakciju podataka iz odabranih radova i pripremu tablica provodi jedna, a statističku obradu druga osoba. Takav „slijepi“ metodološki pristup (engl. blinded analysis) jedan je od važnih kriterija za poboljšanje kvalitete rada.

Rezultati metaanalize najčešće se prikazuju tzv. grafikonom raspona pouzdanosti (engl. forest plot).

\section{Tumačenje rezultata: idu li rezultati u prilog mijenjanja kliničke prakse?}

Uvjerljivo najuzbudljiviji dio rada jest zaključak. Dolazimo do najzanimljivijeg dijela za kliničare - je li potrebno mijenjati pristup nekom problemu, pa tako i kliničku praksu, ili postupati i dalje na način koji se do sada smatrao standardnim? Ako je metodologija izrade sustavnog pregleda zaista temeljita, zaključak možemo smatrati valjanim i rezultat može imati važne implikacije na kliničku praksu, odnosno može utjecati na promjene u načinima liječenja.

\section{Zaključak}

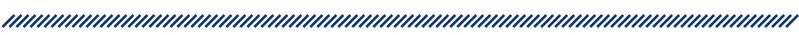

Sustavni pregledi vrsta su članaka kojima se sustavnim pretraživanjem i ocjenom, a katkad i objedinjavanjem rezultata medicinskih istraživanja objavljenih u različitim časopisima, sintetiziraju najbolji rezultati koji mogu dati odgovor na jedno kliničko pitanje te time određuje stupanj znanstvene značajnosti svakog uključenog članka, odnosno zbirna značajnost svih uključenih članaka u rješavanju postavljenoga kliničkog pitanja. Dobro izrađen sustavni pregled tako može ubrzati prijenos znanstveno utemeljenih spoznaja u kliničku praksu². Posljednjih desetak godina broj objavljenih sustavnih pregleda znatno je porastao i u tome ključnu ulogu imaju medicinski časopisi. Tako je, primjerice, PubMed 
sustavnim pregledima ili metaanalizom označio čak 24948 radova objavljenih u medicinskim časopisima indeksiranima tijekom 2015. godine, što je približno $2 \%$ svih indeksiranih radova. $U$ jednoj nedavno objavljenoj studiji istaknuto je da je produkcija sustavnih pregleda $i$ metaanaliza dostigla epidemijske razmjere te da se može pretpostaviti da je većina nepotrebna, dezinformirajuća i/ili konfliktna. Autor studije tvrdi da umjesto promicanja medicinske prakse utemeljene na znanstvenim spoznajama, većina takvih publikacija služi u marketinške svrhe ili kao relativno lak način objavljivanja radova potrebnih autorima za različite svrhe ${ }^{30}$. Sustavni pregledi trebali bi stoga biti ne samo metodološki rigorozno provedeni nego i klinički relevantni te proizlaziti iz istoga problemskog okvira u kojem se kreću primarna klinička istraživanja. Temeljni je cilj dobroga sustavnog pregleda izabrati i vrjednovati najbolje dostupne znanstvene spoznaje koji će se onda u praksi postaviti u kontekst kliničkoga iskustva i osobina pojedinog bolesnika te biti pomoć u donošenju najbolje kliničke odluke.

\section{Literatura}

1. Akobeng AK. Understanding systematic reviews and metaanalysis. Archives of Disease in Childhood. 2005;90:845-8.

2. Wright RW, Brand RA, Warren D, Spindler KP. How to write a systematic review. Clinical Orthopaedics and Related Research. 2007;455:23-9.

3. Cook DJ, Sacket DL, Spitzer WO. Methodological guidelines for systematic reviews of randomized control trials in health care from the Potsdam Consultation on Metaanalysis. Journal of Clinical Epidemiology. 1995;48:167-71.

4. Jarvholm B, Bohlin I. Evidence-based evaluation of information: the centrality and limitations of systematic reviews. Scandinavian Journal of Public Health. 2014;42(Suppl 13):3-10.

5. Sambunjak D, Franić M. Steps in the undertaking of a systematic review in orthopaedic surgery. International Orthopaedics. 2012;36:477-84.

6. Canadian Task Force on the Periodic Health Examination. The periodic health examination. Canadian Medical Association Journal. 1979;121:1193-1254

7. Sackett DL. Rules of evidence and clinical recommendations on the use of antithrombotic agents. Chest. 1989;95:2S-4S.

8. Glass GV, Smith ML. Meta-analysis of research on the relationship of class-size and achievement. Educational Evaluation and Policy Analysis. 1979;1:2-16.
9. The Cochrane Collaboration [Internet]. London: Cochrane Collaboration; 2016. Dostupno na: http://www. cochrane.org/ (pristupljeno 22. lipnja 2016.).

10. Smith R. Much has been achieved, but much remain to be done. British Medical Journal 2013;347:f7383.

11. Lukić IK, Sambunjak D. Types of study design. U: Marušić M, ur. Principles of research in medicine. Zagreb: Medicinska naklada; 2016:53.

12. Akobeng AK. Understanding randomised controlled trials. Archives of Disease in Childhood. 2005;90:840-44.

13. Huić M. Medicina utemeljena na dokazima. U: Marušić M, ur. Uvod u znanstveni rad u medicini. 4. izd. Zagreb: Medicinska naklada; 2008:225.

14. Holly C. Systematic reviews: toward best practice in patient care. Heart \& lung: the journal of critical care. 2012;41:103-4.

15. Franić M, Kujundžić Tiljak M, Požar M, Romić D, Mimica M, Petrak $\mathrm{J}$ et al. Anterior versus posterior approach in 3D correction of adolescent idiopathic thoracic scoliosis: A meta-analysis. Orthopaedics \& Traumatology: Surgery \& Research. 2012;98:795-802.

16. Lang T, Secic M. How to report statistics in medicine. Philadelphia: American College of Physicians; 1997.

17. Higgins J, Green S, ur. Cochrane handbook on systematic reviews of interventions [internet]. London: The Cochrane Collaboration; 2011. Dostupno na: http://handbook. cochrane.org/ (pristupljeno 25. lipnja 2016.).

18. Liberati A, Altman DG, Tetzlaff J, Mulrow C, Gøtzsche PC, loannidis JP et al. The PRISMA statement for reporting systematic reviews and meta-analyses of studies that evaluate health care interventions: explanation and elaboration. PLOS Medicine. 2009;6(7):e1000100.

19. Sampson M, McGowan J. Errors in search strategies were identified by type and frequency. Journal of Clinical Epidemiology. 2006;59:1057-63.

20. Hoogendam A, deVries Robbe PF, Overbeke J. Comparing patient characteristics, type of intervention, control, and outcome (PICO) queries with unguided searching: a randomized controlled crossover trial. Journal of the Medical Library Association. 2012;100:121-6.

21. PubMed [Internet]. Bethesda (MD): U.S. National Library of Medicine; 2016. Dostupno na: http://www.pubmed. com (pristupljeno 22. lipnja 2016.).

22. Scopus [internet]. Amsterdam: Elsevier; 2016. Dostupno na: http://www.scopus.com (pristupljeno 22. lipnja 2016.).

23. CINAHL [internet]. Ipswich (MA): Ebsco Information Services; 2016. Dostupno na: https://www.ebscohost.com/ nursing/products/cinahl-databases/cinahl-complete (pristupljeno 28. srpnja 2016.).

24. Markulin H. Cochrane Library. Mef.hr. 2012;31(1):62.

25. Higgins J, Altman DG. Assessing risk of bias in included studies. Cochrane handbook for systematic reviews of interventions. Chichester: Wiley; 2008.

26. Thacker SB. Meta-analysis. A quantitative approach to research integration. Journal of the American Medical Association. 1988;259:1685-9. 
27. Bartolucci AA. Describing and interpreting the methodological and statistical techniques in meta-analysis. Biochemia Medica. 2009;19(2):127-36.

28. L'Abbe KA, Detsky AS, O 'Rourke K. Meta-analysis in clinical research. Annals of Internal Medicine. 1987;107:22433.
29. Haines T, McKnight L, Duku E, Perry L, Thoma A. The role of systematic reviews in clinical research and practice. Clinics in Plastic Surgery. 2008;35:207-14.

30. Ionnidis JP. The Mass production of redundant, misleading, and conflicted systematic reviews and metaanalyses. Milbank Quarterly. 2016 Sep; 94(3): 485-514. 


\title{
SYSTEMATIC REVIEW - A BACKBONE OF EVIDENCE BASED MEDICINE
}

\author{
1,3 Miljenko Franić \\ ${ }^{1,3}$ Stjepan Dokuzović \\ 2 Jelka Petrak \\ 1 Department of Orthopedic Surgery, \\ Clinical Hospital Dubrava \\ 2 Central Medical Library, \\ University of Zagreb School of Medicine \\ 3 University of Applied Health Sciences, Zagreb
}

\section{Abstract}

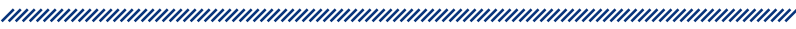

This article gives an overview of the basic principles of systematic reviews and meta-analysis. Important issues that need to be considered when addressing a specific clinical question, collecting published studies, critically evaluating data, and synthesizing research evidence are outlined. The main purpose of this review is to motivate as many healthcare professionals as possible to use the best available evidence in their everyday practice and to make an attempt to produce a quality systematic review as well.

Keywords: systematic reviews, meta-analysis, evidence-based medicine 